\title{
Prevalence of Behavioral Symptoms Leading to Attention Deficit Hyperactivity Disorder (ADHD) Among Grade I Learners
}

\author{
Bernardo Asperin Zabala Jr ${ }^{1}$, Joycel Ann Sta. Ana Manabat. MAEd ${ }^{2, *}$ \\ ${ }^{1}$ Department of Graduate School, Nueva Ecija University of Science and Technology, Cabanatuan City, Philippines \\ ${ }^{2}$ Ulanin - Pitak Elementary School, Department of Education, Ulanin - Pitak, Jaen, Nueva Ecija, Philippines
}

\section{Email address:}

joycelannstaanamanabat@gmail.com (J. A. Sta. A. Manabat. MAEd)

*Corresponding author

\section{To cite this article:}

Bernardo Asperin Zabala Jr, Joycel Ann Sta. Ana Manabat. MAEd. Prevalence of Behavioral Symptoms Leading to Attention Deficit Hyperactivity Disorder (ADHD) Among Grade I Learners. Psychology and Behavioral Sciences. Vol. 6, No. 5, 2017, pp. 70-78. doi: $10.11648 /$ j.pbs.20170605.11

Received: May 18,2017; Accepted: May 27, 2017; Published: September 18, 2017

\begin{abstract}
Every child is a unique individual. The way children act or behave in a particular situation may differ from one another. The study identified the prevalence of ADHD symptoms among Grade I learners as observed by their teachers. Descriptive method was utilized. Questionnaire, interview guide, and observation were the instrument used in 17 respondents. It revealed that academic performance level of identified learners to have ADHD symptoms varies. Learners have low academic performance level while others have average academic performance level. Teachers employed various measures to address identified learners to have ADHD symptoms on aggressiveness, inattentiveness, hyperactivity, impulsiveness and depression. Various management practices were used by Grade I teachers to address identified Grade I learners to have ADHD symptoms on aggressiveness, inattentiveness, hyperactivity, impulsiveness and depression to manage and control the behaviour of their learners. The combination of different management practices served as the best management practices to successfully manage and take control on the behaviour of identified learner.
\end{abstract}

Keywords: Hyperactivity, Impulsiveness, Depression

\section{Introduction}

Every child is a unique individual. The way children act or behave in a particular situation may differ from one another. Educators believe that learners' behavior may affect the education process. Moreover, the learners' ability to learn and the teachers' ability to teach may be influenced by the behavior of the learners in general [1].

Learner's behavior can be considered as one of the most crucial concerns in schools today. Teachers encounter learners' misbehavior on a daily basis [2]. Talking out of turn, disrupting class, being irresponsible or careless, disobeying rules and whining, bullying, fighting, defiance and lying, can start out small, but escalate into more serious problems if not dealt with properly are some of the behavioral problems that learners exhibit [3]. These are ADHD symptoms on aggressiveness, inattentiveness, hyperactivity, impulsiveness and depression which are quite alarming [4].

The researchers observed that some of the learners today exhibit behavioral symptoms leading to Attention Deficit/Hyperactivity Disorder (ADHD) such as aggressiveness, inattentiveness, hyperactivity, impulsiveness and depression which interfere with the learning process of the learners inside the classroom [5].

Learners with ADHD symptoms in general may possibly experience failures in school and at home [6]. They may experience underachievement, under performance, rejection, and other behavioral problems that may affect their lives throughout their adulthood. Deeply understanding the causes of these misbehaviors and how to deal with the learners can make a classroom flow smoothly as possible.

This study was conducted to help Grade I teachers to identify which among their learners exhibit behavioural 
symptoms leading to Attention-Deficit/Hyperactivity Disorder. What are the most effective measures and management practices to help teachers to properly handle their learners with ADHD symptoms and what policy can be recommended for teachers in a regular class to manage learners with ADHD symptoms?

\section{Objectives}

To identify the prevalence of ADHD symptoms among Grade I learners as observed by their teachers, determine the academic performance level of learners with ADHD symptoms, determine the measures employed by the Grade I teachers to address the ADHD symptoms among their learners; and identify the management practices employed by the teachers to address the behavioral symptoms for ADHD [8].

In attaining the directions and objectives of this study, the researcher used as basis the Department of Education Order No. 72. S. 2009 entitled Inclusive Education as Strategy for Increasing Participation Rate of Children. Inclusive education is defined as a process of including learners with special needs, specifically the identified learners with ADHD symptoms in a regular classroom situation to achieve their optimum level of potentials [9]. A comprehensive inclusive program for children with special needs has five main components as follows: Child Find. This is locating where these children are through family mapping survey, networking campaigns, and networking with the local health centres. Assessment. This is a continuous process of identifying the strengths and weaknesses of the child through the use of formal and non-formal tools for proper program grade placement. Program Options. Regular schools with or without trained SPED Teachers shall be provided educational services to children with special needs. Curriculum Modifications. This shall be implemented in the form of adaptations and accommodations to optimum learning based on individual's needs and potentials. Parental Involvement. This plays a vital role in preparing the children for academic, moral and spiritual development. Administrators, Regular Teachers and SPED teachers play vital roles in the implementation of inclusive education.

Administrators strictly observed that a maximum of two learners with special needs like those learners to have identified with ADHD must be included in a regular class. They should also conduct in-service training on curriculum modification, plans programs and activities where regular and special learners can work and perform together, monitors the services rendered by the regular teachers, SPED teachers, other school personnel and commend their support and dedication, and establish linkages with government and non-government institution for the continuous support on resources to make the implementation of inclusive education successful.

The role of the regular teachers on the implementation of inclusive education are: welcome the learners as official enrolees in regular class, facilitate the implementation of special education program, coordinate with the SPED teacher for curriculum modifications, model appropriate ways of developing relationships with children with special needs, and help secure special equipment and materials.
The SPED teachers have numerous roles on the implementation of inclusive education, such as: provide continuing support to the inclusive education program, provide technical assistance on the use of the appropriate materials and equipment, prepare checklist of expected academic and behavioural outputs for monitoring, provide services to school when training is needed, use teaching strategies and skills development activities to meet the learners' needs, and develop individualized Education Program (IEP) in consultation with the regular teachers, parents and other professionals

Inclusive education is a big challenge for regular teachers who must cope with the changes in curriculum to provide activities where regular and special learners can work and perform together. Their management practices may also change to cater the diversity of learners.

The inclusive education program will help special learners particularly those with ADHD symptoms, who most of the time were mistakenly called by their teachers, parents, and relatives as hard-headed because of their extreme behavioural problems, when in reality they are suffering from serious mental disorder. In remote areas, communities are not aware of this mental disorder. Due to this, the learners were sent to regular class and were treated as normal learners which are quite alarming [10].

\section{Methodology}

\subsection{Methods}

The descriptive method of research was utilized. It was conducted in six (6) purposely selected public elementary schools at Jaen District, Jaen, Nueva Ecija, Philippines. The respondents were Grade I teachers and Grade I learners identified to have ADHD symptoms. The distributions of teacher and learner respondents per school are as follows respectively; under Jaen Central School 1 teacher and 2 learners, Niyugan Elementary School, 1 teacher and 1 learner, Sto. Tomas South Elementary School, 2 teachers and 2 learners, Hilera Elementary School, 1 teacher and 1 learner, Ulanin - Pitak Elementary School, 1 teacher and 3 learners and Marawa Elementary School, 1 teacher and 1 learner.

Questionnaire, interview guide, and observation were then instrument used. Permission from Schools Division Superintendent, District Supervisors and School Heads of the elementary schools in Jaen was sought before the administration of the instruments.

\subsection{Statistical Analysis of Data}

The prevalence of ADHD symptoms was described textually by cases as follows. Case I - The learner was identified with four (4) ADHD symptoms. Case II- The learner was identified with three (3) ADHD symptoms Case III- The learner was identified with two (2) ADHD symptoms, Case IV- The learner was identified with one (1) ADHD symptoms. The measures employed by the Grade I teachers to address the identified learners to have ADHD 
symptoms were textually presented and interpreted by cases. The management practices employed by the Grade I teachers were textually presented and interpreted by cases.

\section{Results}

The Prevalence of ADHD Symptoms among Grade I Learners.

Table 1. Distribution of Teacher-Respondents, Their Learners with Identified ADHD Symptoms.

\begin{tabular}{|c|c|c|c|}
\hline School & Teacher & Learner & ADHD Symptoms \\
\hline 1. Marawa Elementary School & 1 & A & $\begin{array}{l}\text { Aggressiveness } \\
\text { Hyperactivity Impulsiveness Depression } \\
\text { Inattentiveness }\end{array}$ \\
\hline 2. Niyugan Elementary School & 2 & B & $\begin{array}{l}\text { Hyperactivity } \\
\text { Impulsiveness }\end{array}$ \\
\hline 3. Hilera Elementary School & 3 & $\mathrm{C}$ & $\begin{array}{l}\text { Inattentiveness } \\
\text { Hyperactivity }\end{array}$ \\
\hline 4. Jaen Central School & 4 & $\mathrm{D}$ & $\begin{array}{l}\text { Hyperactivity } \\
\text { Impulsiveness }\end{array}$ \\
\hline & & $\begin{array}{l}J \\
E\end{array}$ & $\begin{array}{l}\text { Impulsiveness } \\
\text { Inattentiveness }\end{array}$ \\
\hline 5. Ulanin-Pitak Elementary School & 5 & $\begin{array}{l}F \\
G\end{array}$ & $\begin{array}{l}\text { Inattentiveness } \\
\text { Inattentiveness }\end{array}$ \\
\hline 6. Sto. Tomas South Elementary School & $\begin{array}{l}6 \\
7\end{array}$ & $\begin{array}{l}\mathrm{H} \\
\mathrm{I}\end{array}$ & $\begin{array}{l}\text { Impulsiveness } \\
\text { Impulsiveness }\end{array}$ \\
\hline
\end{tabular}

Table 1 shows the identified schools, identified seven Grade I learners identified to have ADHD symptoms as enumerated in the table. The prevalence of behavioral symptoms leading to Attention-Deficit/Hyperactivity Disorder was the least among the learners in each school.

\section{Discussion}

\section{Case I- Learners with Four (4) ADHD Symptoms}

Learner A was identified with four (4) ADHD symptoms, namely: aggressiveness, hyperactivity, impulsiveness and depression. He is a 6-year old, male, and the youngest of the two children of a farmer and a full time housewife. According to his teacher, he usually starts the fight without valid reasons to the point that he physically hurt his classmates through the use of certain weapons like sharp pointed pencil, ball pen and others. He habitually bullies his classmates by means of hitting, destroying his classmates' properties and stoling items of nontrivial values. The learner seems very cruel to animals and has engaged in fire setting which can cause serious damage whether intentionally or unintentionally.

During group activity, he easily gets angry over simple things. He seems very domineering during play as observed by the teacher. Consequently, he always loses his temper easily to the point that he could possibly attack his classmates and teacher. He also tends to defy or refuse to comply with adult's request or rules.

Learner A was also identified with ADHD symptom on hyperactivity. He fidgets with hands, feet and squirms in seat. He tends to leave the seat near his teacher in which he was expected to be seated. He has difficulty playing or engaging in leisure activities, runs and climbs excessively, talks excessively, and blurts out inappropriate comments which negatively affect teaching-and-learning process. Also, he has difficulty waiting in line to the point that he seems very annoyed and distracted.
Another ADHD symptoms exhibited by learner A are impulsiveness and depression. He is impulsive to the point that he acts without consideration of the consequences of his actions and rushes through tasks which usually resulted to poor academic output. Also, he seems afraid to try new things due to fear of making mistakes and has serious self struggles. He feels unloved, unwanted, lonely, guilty and depressed which are the symptoms of one of the prevalence of ADHD which is known as depression.

\section{Case II-Learners with Three (3) ADHD Symptoms}

Only one learner was identified to have three ADHD symptoms, which are: inattentiveness, hyperactivity and impulsiveness.

Learner B is a 6-year old, male, and the only child of a driver and a full time housewife. Based on the information given by the teacher, he is not ordinary in both physical and mental aspects like others. His teacher revealed that his parents are surely aware that their child is quite different unlike other normal child, but they are just ignoring the fact that their child needs special attention and education.

He has difficulty sustaining attention to tasks or any school activity which resulted to habitual mistakes in school works, homework and activities both in group and individual activities. He has difficulty in organizing tasks and activities which resulted in loosing things necessary for tasks/activities given. He, on the other hand, fails to follow direction or instructions with or without reminders because he seems easily distracted by extraneous stimuli. His teacher added that learner B seems very preoccupied by his own thinking. He just did what he is thinking. Consequently, he could hardly focus on things around him and does not seem to listen when spoken to directly. These behaviors are the ADHD symptom on inattentiveness.

The learner fidgets with hands, feet and squirms in seat. He has the tendency to leave the seat expected of him, talks excessively, runs about or climbs excessively, and interrupts or intrudes on others by means of blurting inappropriate 
comments. Also, he has difficulty waiting in line and engaging in leisure activities which effects teaching-andlearning process negatively. The behaviors exhibited by the learner as observed by his teacher are ADHD symptom on hyperactivity.

Another behavioral symptom of ADHD exhibited by the learner is impulsiveness. He tends to act without consideration to the consequences. He usually makes irrational decisions like throwing objects when he gets mad and seems very impatient. He habitually blurts out inappropriate comments during class discussion which may cause interruption of active discussion. He, also, has this habit of telling lies just to obtain goods for favors and to obtain obligations which is quite alarming. For instance, he was caught punching his classmates directly on the face but he would just repeatedly deny the truth and keep on blaming others. He thought that blaming others would save him from the mistakes he did and he seems not guilty about it.

\section{Case III- Learners with Two (2) ADHD Symptoms}

Two learners were identified to have two ADHD symptoms.

Learner $\mathrm{C}$ was identified to have symptoms on inattentiveness and hyperactivity, while Learner $\mathrm{D}$ was identified to have symptoms on hyperactivity and impulsiveness.

Learner $\mathrm{C}$ is a 7-year old, male, and the eldest of the two children of a driver and a full time housewife. He seems not normal like other learners of his age. He has a speech defect wherein he cannot construct simple sentences orally. He could hardly express himself through verbal communication. "A-in ka? (Kakain ka?), Tom-ba? (Gusto mo ba?), ako uwi (Uuwi ako)", were some of the phrases that the learner used in expressing himself.

His attention span is quite short. During class discussion or in any individual and group activity, he fails to give attention to details and have difficulty in sustaining attention to tasks or any given activities in school. Due to the reasons being mentioned, the learner fails to finish school work whether it is individual or group work, homework, and other school related activities which negatively influence teaching-andlearning process. Learner $\mathrm{C}$ seems dreamy or unfocused to the extent that the teacher is reminding the learner frequently to pay attention to class discussion and activities. He does not seem to listen when spoken to directly, does not follow instructions or it might be because the learner has difficulty comprehending on the direction/instruction being given by the teacher yet the instruction is so simple.

He needs frequent reminders while having individual or group activity, otherwise he will be distracted by extraneous stimuli and will be having difficulties in organizing the tasks or activities. However, despite of the teacher's frequent reminders during activity the learner frequently fails. One of the biggest problems being encountered by the teacher is when learner D seems like avoiding tasks that require mental effort. This is the reason why he has difficulty in reading and comprehension which is the required competencies for all Grade I learners. These behaviours displayed by Learner C are ADHD symptom on inattentiveness.

He also displayed ADHD symptom on hyperactivity. The learner has trouble sitting still, fidgets with hands, feet and squirms in seat. Then to resolve these behaviors being displayed by learner $\mathrm{C}$, the teacher prepared seat for learner $\mathrm{C}$ next to her. In this situation, the teacher can handle the behavior of the learner so easily. However, the learner always leaves the seat expected for him and just has fun in running or climbing excessively. In addition, Learner $\mathrm{C}$ has difficulty waiting in line as instructed. Furthermore, during class discussion, the learner interrupted the class by means of blurting out answers before questions have been completed, while during group activities the learner tend to butt into conversation or blurts out inappropriate comments. He tends to be physically cruel to his classmates by means of stabbing his classmates using pointed pencil as his weapon, throwing properties of others, destroyed someone else's property and the likes.

Learner D was identified to have symptoms on hyperactivity and impulsiveness. He is a 6-year old, male, and the youngest of the four children of a vendor and a full time housewife. Based on the information given by his teacher, he was identified to have symptoms on hyperactivity and impulsiveness. He has trouble in sitting still, fidgets with hands and feet, and squirms in seat which seems that the learner can't stay any longer in any position. He has no one to play with in their house which may be the main reason why he's making the classroom as his playground- running and climbing excessively. He also has difficulty waiting in line as clearly observed during flag ceremony and supervised recess. He seems anxious and cannot stay on the position expected for him. Moreover, during class discussion the learner keeps on blurting out answers before the questions have been completed. Furthermore, the learner has the tendency to keep on interrupting his classmates or intrudes on his classmates.

Another behavioral symptoms displayed by learner D is impulsiveness. He tends to throw any objects in front of him the moment he got angry. Also, the learner always rushes through tasks and act without much consideration to the consequences. Moreover, the learner lies to obtain goods for favors and to obtain obligations without considering other people. He also blurts out inappropriate comments during class discussion or in any activities interrupting the whole teaching-and-learning process.

\section{Case IV-Learners with One (1) ADHD Symptom}

Six learners were identified to have one (1) ADHD symptom.

Learner $\mathrm{E}$ was identified to have a symptom on inattentiveness. He is a 6-year old, male, and the second child of the four children of a servant and a full time housewife. According to his teacher, Learner E fails to give attention to details and has difficulty sustaining attention to tasks or activities in school. Due to these reasons, he makes careless mistakes in school work and worst he fails to finish school works, homework and other school-related activities that require sustained mental effort. Also, he has the tendency to 
lose things necessary for tasks or activities in school or being forgetful in daily activities in school. He does not seem to listen when spoken to directly. It seems like he is distracted by extraneous stimuli. Furthermore, it is quite noticeable that the learner seems dreamy or unfocused that's why he frequently misses bits of information needed for tasks and homework. Summarily, the teacher observed that the learner has a quiet short attention span. He could hardly finish any classroom activity like writing and drawing.

Learner $\mathrm{F}$ was identified to have ADHD symptom on inattentiveness. She is a 6-year old, female, and the second child of the four children of a part-time farmer and a full time housewife. According to her teacher, she seems dreamy or unfocused to the extent that the teacher is reminding the learner frequently to pay attention to class discussion and activities. He also does not seem to listen when spoken to directly, does not follow instructions or it might be because the learner has difficulty comprehending the direction/instruction being given by the teacher yet the instruction is so simple. In addition, she needs frequent reminders while having individual or group activity; otherwise the learner will be distracted by extraneous stimuli and will be having difficulties in organizing the tasks or activities. However, despite of the teacher's frequent reminders during activity the learner frequently fails. One of the biggest problems being encountered by the teacher is when learner $\mathrm{F}$ seems like avoiding tasks that require mental effort. This is the reason why learner $\mathrm{F}$ has difficulty in reading and comprehension which is the required competencies for all Grade I learners. These behavioural symptoms displayed by learner $\mathrm{F}$ is inattentiveness.

Learner $G$ was identified to have ADHD symptom on inattentiveness. He is a 6-year old, male, and the youngest of the four children of a sari-sari store owner. According to his teacher, he has difficulty sustaining attention to tasks or any school activity which resulted to habitual mistakes in school works, homework and activities both in group and individual activities. Also, he has difficulty in organizing tasks and activities which resulted in loosing things necessary for tasks/activities given. He fails to follow direction or instructions with or without reminders because he seems easily distracted by extraneous stimuli. His teacher added that learner $\mathrm{G}$ seems very preoccupied by his own thinking. He just did what he is thinking. Consequently, he could hardly focus on things around him and does not seem to listen when spoken to directly.

Leaner $\mathrm{H}$ was identified with ADHD syndrome on impulsiveness. He is a 7-year old, male, and the oldest of the two children of a farmer and a full time housewife. He is one of the beneficiaries of 4 P'S. It is a government program which aims to (a) help indigent families by means of giving allowances for their children and (b) reduce drop-out rates. According to his teacher, he habitually throws objects whenever he gets mad which sometimes cause destruction of things or objects he throws. He rushes through tasks both in individual and group activities which may lead to poor academic outputs. He tends to act without consideration of the consequences. For instance, he thought he is just being playful with his classmates in a drastic way which most of the time causes serious harm to his classmates. He seems very impatient during class discussion or in any group activities and blurts out inappropriate comments which highly disrupted class discussion. Learner $G$ has this habit of telling lies just to obtain goods for favours and obtain obligations which is quite alarming.

Learner I was identified with a symptom on impulsiveness. He is a 6-year old, male, and the only child of a farmer and a full time housewife. According to his teacher, he tends to throw any objects in front of him the moment he gets angry/mad. Also, he always rushes through tasks and acts without much consideration to the consequences. Moreover, he keeps on lying to obtain goods for favors and to obtain obligations without considering other people. He also blurts out inappropriate comments during class discussion or in any activities which may cause frequent interruption of classes.

Learner $J$ was identified with a syndrome on impulsiveness. He is 7-year old, male, and the older of the two children of a farmer and a full time housewife. According to his teacher, he tends to act without consideration to the consequences. He usually makes irrational decisions like throwing objects when he gets mad and seems very impatient to the point that he cannot stay for a long period of time standing as instructed, he cannot stay longer in a situation like working with his group mates or completing certain tasks alone. He habitually blurts out inappropriate comments during class discussion which may cause interruption of active discussion. He, also, has this habit of telling lies just to obtain goods for favours and to obtain obligations which is quite alarming.

Academic Performance Level of Identified Learners with ADHD Symptoms

Learner A has a general average of 78 with a qualitative rating of "Fairly Satisfactory". According to his teacher, his academic performance level is negatively influence by his behaviour. Most of the time, he fails to finish school activities and other related school activities. The teacher described learner A as a "slow learner". He is not focused and seems not interested to learn.

Learner B has a general average of 77 with a quantitative rating of "Fairly Satisfactory". His teacher mentioned that he really needs special attention and treatment and must attend special class, but his parents refused the idea that their child has special needs that can no longer be provided in a regular classroom situation. The learner habitually ignores classroom activities and other related school works. He just keeps on roaming in the four corners of the classroom which is very unnecessary. In addition, he has the habit of throwing crumpled papers in no particular form and in no particular direction. His behavioural problems negatively influence teaching-and-learning process.

Learner $\mathrm{C}$ has a general average of 76 with a qualitative rating of "Fairly Satisfactory". According to his teacher, the learner has difficulty in expressing himself through oral and written communication. He has a speech defect wherein he 
cannot form even a simple sentence in expressing himself orally nor in written form. He was described by his teacher as a "slow learner".

Learner D was given a quantitative rating of 80 with a qualitative rating of "Satisfactory". According to his teacher, he is capable to learn but his playful attitude impedes his growth as a learner. Most of the time, his attention was diverted to various extraneous stimuli because of sudden boredom during class hours. However, if he would be serious and focused during class discussion or in any classroom related activities he would be able to cope with the lesson easier. To sum up, he can read, write legibly and count which are the expected skills for all Grade I learners. He was described by his teacher as an "average learner".

Learner E has a general average of 75 with a qualitative rating of "Fairly Satisfactory". According to his teacher, he frequently leaves unfinished written works, group activities, individual activities and fails to submit his homework. Also, he seems not interested to learn. He has a short attention span and could hardly write or draw. He can't read either at the moment and just recognized few letters in the alphabet. His inattentiveness stops him from engaging himself even more to educative process which resulted to poor academic output. He was described by his teacher as a "slow learner".

Learner $\mathrm{F}$ was given a quantitative rating of 76 with a qualitative rating of "Fairly Satisfactory". According to her teacher, the learner can recognize basic words in Filipino but the learner cannot read and comprehend in any Filipino and English passages. Also, the learner cannot answer the guide questions being asked after listening to a story or short passages. The learner has difficulty in recognizing and counting numbers from 0 to 10 and beyond. Moreover, the learner has a short attention span is preventing her to grow academically. She was described by her teacher as a "slow learner".

Learner G has a general average of 77 which is "Fairly Satisfactory". His teacher mentioned in the interview conducted by the researcher that he can scribe legibly if he is in the mood. Also, he can read simple sentences in Filipino but could hardly read English sentences/passages. His attention span is short, most of the time leads to various negative effects in educative process like unable to finish individual and group activities, homework and other related classroom activities which resulted to low performance level at school.

Learner $\mathrm{H}$ has a quantitative rating of 82 with a qualitative rating of "Satisfactory" as of third quarter. He was described by his teacher as an "average learner" in terms of academic performance level. He can express himself by means of verbal communication but he has difficulty in reading complex passages both in Filipino and English. His inattentiveness stops him to achieve his optimum level of development as a learner. Despite of things being mentioned, the amazing thing about him is his passion in drawing.

Learner I have a general rating of 81 which is qualitatively rated as "Satisfactory". His general average revealed that his academic performance level is average like what his teacher mentioned during the interview. He is an "average learner". He can comprehend on the lesson being taught by the teacher but due to extraneous stimuli his focus and attention were diverted on unnecessary things like chatting with his classmates and playing around. These reasons negatively affect the academic performance of the learner being mentioned to the point that he was not able to finish school works and any given activities. He is poor in written works but do great in oral. Furthermore, he can read in Filipino but could hardly read in English.

Learner $\mathrm{J}$ has an average of 81 with a qualitative rating of "Satisfactory". According to his teacher, he can read, write and count which are the basic learning competencies that a Grade I learner must acquire. However, his impulsiveness negatively affects the whole teaching-and-learning process. His teacher described him as an "average learner".

The academic performance level of identified learners to have ADHD symptoms varied, most of them have low academic performance level but others belong to under average level.

\section{Measures Employed by the Grade I Teachers to Address Identified Learners with ADHD Symptoms \\ Case I-Measures Employed by Teacher 1 to Learner A}

Teacher 1 has employed various measures to address Learner A who was identified to have syndromes on aggressiveness, hyperactivity, impulsiveness and depression. Learner's aggressiveness was addressed by means of giving frequent reminders not to harm his classmates or make any action which might result to untoward incident like causing fire. She often reminds the learner to think first of the consequences of his action before doing anything. Also, she always makes sure that her learner is near her table so that there would be a little chance or tendency that the learner would start a fight.

According to teacher 1, when it comes to the learner's hyperactivity, calling the name of learners from time to time awakens him that he's still in the classroom and must follow the rules and his obligations as a learner. It serves as reminder for the learner not to do necessary actions and focus instead on the given tasks. The impulsiveness of the learner was addressed by teacher 1 by means of frequently giving instructions/directions which may guide him in doing the given tasks. Close supervision was also employed by the teacher to avoid learner A in rushing things which may lead to poor academic output. His teacher addressed his depression by means of having friendly conversation to gain his trust. Gaining the learner's trust would be the best way in helping him cope with his depression.

\section{Case II-Measures Employed by Teacher 2 to Learner B}

Learner B was identified to have three ADHD symptoms on inattentiveness, hyperactivity and impulsiveness. To address his prevalent symptoms leading to ADHD, teacher 2 employed various measures. Learner's inattentiveness was addressed by his teacher by means of giving verbal encouragement to show active participation in classroom activities. His hyperactivity was addressed by his teacher by giving him extra attention. Simply, his teacher gives close 
supervision and frequent reminders to help him finish the given classroom tasks. Teacher 2 addressed the learner's impulsiveness which resulted to careless mistakes in classroom activities by means of recognizing him for the good things he has done. Recognition was made in two different forms: giving positive praises and giving tokens like candies and the likes.

Case III-Measures Employed by Teacher 3 to Learner C

Learner $\mathrm{C}$ was identified to have symptoms on inattentiveness and hyperactivity. Teacher 3 employed various measures in addressing learner's hyperactivity. As the learner roamed around the classroom during class activities, she tried to get his attention by means of calling his name. Then, she would start a friendly conversation to encourage him to stop roaming around and stay focus on his task. Another measure employed by teacher 3 in addressing learner's inattentiveness is by means of giving rewards in a form of praises and tokens when he did something good or as he finished his task.

\section{Case IV-Measures Employed by Teacher 4 to Learner D} and $J$

Learner D was identified to have syndromes on hyperactivity and impulsiveness. His hyperactivity and impulsiveness in class were addressed by Teacher 4 by means of giving him a chance to lead in group activities. Also, she visited and talked to the learner's parents at home to promote camaraderie in guiding the learner. Impulsiveness of Learner $\mathrm{J}$ was addressed by Teacher 4 by means of giving him the opportunity to lead a group. Also, home visitation was made to ensure that there would be a follow-up intervention on the learner's attitude at home.

Case V-Measures Employed by Teacher 5 to Learner E, F and $\boldsymbol{G}$

Learner $\mathrm{E}, \mathrm{F}$ and $\mathrm{G}$ were identified with ADHD symptoms on inattentiveness. These three learners to have identified with ADHD symptom were addressed by Teacher 5 differently. Learner E seems not interested in any classroom activities so that the teacher keeps on getting his attentions by all means like calling his name, giving frequent reminders and the likes. While, inattentiveness of Learner $\mathrm{F}$ was handled by her teacher through giving ample time to finish the given activity and talk to her that the output of her work is important. Meanwhile, since Learner G wants to be praised and be acknowledged for his good deeds, so his teacher keeps on giving him words of encouragement and keeps on praising him for him to strive even harder.

Case VI-Measures Employed by Teacher 6 to Learner $\mathrm{H}$

Learner $\mathrm{H}$ impulsiveness was addressed by teacher 6 by means of helping him realized his mistakes as he hurt the feelings of his classmates due to his careless actions. Also, she advised her learner to keep calm and think on the effects of his actions before doing anything else.

Case VII-Measures Employed by Teacher 7 to Learner I

Learner I was identified with impulsiveness symptom of ADHD. Teacher 7 addressed Learner I by means of giving proper attention by his teacher in handling his impulsiveness. One of the measures she employed in addressing her learner's impulsiveness was to give close supervision to avoid careless mistakes in classroom activities.

Management Practices Employed by the Grade I Teachers to Address Identified Learners with ADHD Symptoms

Case I- Management Practices Employed by Teacher 1 to Learner $A$

Teacher I employed various management practices to address Learner A's ADHD syndromes on aggressiveness, impulsiveness, hyperactivity and depression. The first and foremost action done by teacher 1 in addressing the aggressiveness of the learner was home visitation. She visited the learner at home and asked personal questions to parents concerning their child. She gathered every bit of information on the learner and used those information to successfully address the behaviour of the learner. To address the impulsiveness of the learner, there were numerous instances that she assigned the learner to lead a group which may lead to learner's encouragement to cooperate in a group since he has a responsibility as a leader. Also, she used calm voice to help the learner calm down whenever the learner loses his temper because angry voice or authoritative voice wouldn't cause any good. The management practices employed by teacher 1 to address learner's hyperactivity were kept on reminding the rules that must follow inside the classroom. She, as a teacher, asked all the learners to treat Learner A as their friend which was her way to address the depression of the learner. Also, she often called the learner by his name so that the learner may feel that he is important. According to her, there would be no single best management practice that can be employed in handling learners with ADHD symptoms but the combination of different practices or strategies appropriate to the learner would be better.

Case II-Management Practices Employed by Teacher 2 to Learner $B$

Teacher 2 employed various management practices to address the ADHD syndromes on inattentiveness, hyperactivity and impulsiveness of Learner B. To address the learner's inattentiveness, she set the mood of the learner by means of giving proper motivation before the start of each lesson. The moment that the interest and attention of the learner was caught there would be a greater chance that the learner would listen to the discussion. Unfortunately, when the learner's attention wasn't caught at the beginning of the lesson then the learner would just start to crumple papers in no particular form and would just throw those papers in no particular directions. Then, the learner would not be listening until the day ends. She gave a minimal number of directions to ensure that the learner fully understood the tasks to be done and asked learner to repeat the directions to the teacher to ensure validity of the directions. Consequently, positive motivation is very important to positively address the learner's inattentiveness.

According to teacher 2, there were various management practices she employed to address the learner's hyperactivity. She prepared a seat near to her table for the learner. Through this simple way, she was able to monitor the learner and avoided untoward incidents due to learner's hyperactivity. 
Also, she made repeated instructions for so many times so that the learner's attention was drawn back to tasks. The management practices employed by the teacher to address the learner's impulsiveness were the use of recognition in a form of praises and tokens of appreciation for his good deeds.

Case III-Management Practices Employed by Teacher 3 to Learner $C$

Teacher 3 employed various management practices to address the ADHD syndromes on inattentiveness and hyperactivity of Learner $\mathrm{C}$. As a teacher, she only wants the best for her learners. However, there were few learners who seemed not interested in schooling specially learner $\mathrm{C}$. There were instances that she screamed or shouted, got angry with and frequently called the name of the learner just to get the learner's attention. She tried a lot of ways to address the hyperactivity of her learner but the management practices she employed failed to do its purpose except in one and that was having sitting arrangement wherein the learner sat next to her. In this way, she has full control on the behaviour of the learner. To address the inattentiveness of her learner, she defined the appropriate behaviour that must be done by learner $\mathrm{C}$ and promised to give rewards as the learner did what is expected of him. Also, she used specific and direct instructions so that the learner may focus on the expected outcomes of the task given.

Case IV-Management Practices Employed by Teacher 4 to Learner $D$ and $J$

Learner $\mathrm{D}$ and $\mathrm{J}$ have ADHD syndromes which were addressed by Teacher 4 differently. Learner D was identified to have syndromes on hyperactivity and impulsiveness. Teacher 4 managed the hyperactivity of Learner D through a sitting arrangement where learner $\mathrm{D}$ is expected to seat next to her. According to her, in this simple way she could possibly monitored the learner and may avoid untoward incident. She usually stands close when giving instruction and tried to maintain eye contact so that the learner may focus on the expected outcome of the task given. Teacher 4 also said that with regards to the learner's impulsiveness, a friendly conversation with the learner did help. She gave friendly reminders on certain scenario that would cause serious harm for others and for the learner itself if the learner would be careless in making decisions. She added that she could see that the learner seemed taking the reminders seriously and rapid changes on the learner can be seen, but she can't denied the fact that there were times that the learner tends to act without so much consideration. Also, scheduled home visitations to promote camaraderie between the teacher and the parents concerning the learner helped.

Learner $\mathrm{J}$ was identified with ADHD symptom on impulsiveness. Teacher 4 addressed this learner differently. Sometimes, she let the learner led a group to make the learner feel that his decisions and actions are important so that he must be very patient and careful in doing the given tasks. Also, she reminded the learner to avoid throwing objects because it might cause serious harm to others or might destroy school property.

Case V-Management Practices Employed by Teacher 5 to Learner $E, F$ and $G$
Learner E, F and $G$ were identified to have ADHD symptom on inattentiveness. Despite of having the same ADHD symptoms, Teacher 5 employed different management practices to address the inattentiveness of each learner. According to her, no two people are exactly alike so that the learners' inattentiveness must be addressed differently concerning the learner as an individual with unique needs and capabilities.

She frequently called the name of Learner E during classroom activities and asked if the learner is already done with the tasks. By means of giving close supervision, Learner E might possibly finish the given tasks. Also, before the task started, the teacher talked to Learner E and reminded the learner that she is interested to the output so that he must focus and put extra effort on the given tasks. Also, she often touched the shoulder of the learner when giving instructions so that the learner may feel comfortable with his teacher and which may lead to positive outcomes.

The management practices she employed to address the inattentiveness of Learner $\mathrm{F}$ is somehow similar to the Learner E. She kept on telling to Learner $F$ that the output of her work is important to encourage the learner to do her task. Also, she gave specific and direct instruction so that the learner wouldn't have difficulties in understanding the directions on the given tasks. Often called the name of the learner during activities may also engage learner to be focused on the activities.

Learner $G$ was addressed by his teacher by means of reward system. She noticed that simple praises and tokens of appreciation motivated the learner to do his task even better.

Case VI- Management Practices Employed by Teacher 6

\section{to Learner $\mathrm{H}$}

Teacher 6 addressed the impulsiveness of Learner $H$ by means of having friendly reminders to think first before doing anything. The learner was also given close supervision during activities and frequently called the name whenever he was noticed to be very impatient and act without much consideration to the consequences. Every morning, before the lesson starts they have what so called "story-telling" wherein she narrates a certain scenario that could possibly happen in a classroom about being impulsive and its negative effect. Story telling surely caught the interest of the impulsiveness of the learner and the other learners as well. That story telling served as a motivation for all learners. Also, she scheduled home visitations to solicit information on the learner so that the root of the learner's impulsiveness can be determined. Once the root has been determined, effective management practices can now be employed.

Case VII-Management Practices Employed by Teacher 7 to Learner I

Learner I was identified to have ADHD symptom on impulsiveness. Teacher 7 addressed the learner's impulsiveness by means of giving close supervision during classroom activities. Also, she prepared a seat for the learner next to her to ensure that the learner would not make careless actions. Also, frequent reminders were given to the learner to avoid rushing through tasks and were asked to concentrate on the given tasks. Another management practice employed by 
Teacher 7 to address the ADHD symptom on impulsiveness was having a friendly conversation to remind the learner to avoid blurting inappropriate comments during class discussion or to his classmates which may cause interruption of classes.

\section{Conclusions}

There was a prevalence of having one learner with ADHD symptoms in each school-respondent.

The academic performance level of identified learners to have ADHD symptoms varies. Most of the identified learners have low academic performance level while others have average academic performance level. Teachers employed various measures to address identified learners to have ADHD symptoms on aggressiveness, inattentiveness, hyperactivity, impulsiveness and depression. The measures employed by the teachers helped them manage the ADHD symptoms of learners to reinforce positive behaviours of learners and improve the academic performance level. Various management practices were used by Grade I teachers to address identified Grade I learners to have ADHD symptoms on aggressiveness, inattentiveness, hyperactivity, impulsiveness and depression to manage and control the behaviour of their learners. The combination of different management practices served as the best management practices to successfully manage and take control on the behaviour of identified learner.

\section{References}

[1] Cole, R. W. (2013), Educating Everybody's Children: Diverse Teaching Strategies for Diverse Learners, Revised and Expanded 2nd Edition, ASCD Publication, http://www.ascd.org/publications/books/107003/chapters/Educ ating-Everybody's-Children@-We-Know-What-

Works\%E2\%80\%94And-What-Doesn't.aspx Date Retrieved: January 22, 2017.
[2] Sun, R. C. and Shek, D. T. (2012), Student Classroom Misbehavior: An Exploratory Study Based on Teachers' Perceptions, The Scientific World Journal, Volume 2012 (2012), Article ID 208907, 8 pages, http://dx.doi.org/10.1100/2012/208907 Date Retrieved: January 22, 2017.

[3] Anderson, M. (2013), Behavior Problems in Elementary School, Our Everyday Life, http://oureverydaylife.com/behavior-problems-elementaryschool-11970.html Date Retrieved: January 25, 2017.

[4] American Psychiatric Association (2013). Diagnostic and Statistical Manual for Mental Disorder ( $5^{\text {th }}$ ed.). Washington, DC: Author. Date Retrieved: January 25, 2017.

[5] American Psychiatric Association. (2000). Diagnostic and statistical manual of mental disorders (4th Edition., text revision [DSM-IV-TR]) Date Retrieved: January 22, 2017.

[6] Appalachia Educational Laboratory (2012), ADHD: Building Academic Success, www.ldonline.org/article/ADHD\%3A_Building_Academic _Success Date Retrieved: January 26, 2017.

[7] Adelman, H. and Taylor, L. (2015), Conduct and Behavior Problems: Intervention and Resources for School Aged Youth, School Mental Health Project, Dept. of Psychology, UCLA, http://smhp.psych.ucla.edu/pdfdocs/conduct/conduct.pdf

[8] Polanczyk, G., de Lima, M. S., Horta, B. L., Biederman, J. and Rohde, L. A. (2007). The Worldwide Prevalence of ADHD: A Systematic Review and Metaregression Analysis. The American Journal Of Psychiatry, Volume 164 Number 6.

[9] Manansala, Maryola A. and Dizon, Edilberto I. (2009). Shadow Teaching Scheme for Children with Autism and Attention Deficit-Hyperactivity Disorder in Regular Schools. A Published Thesis: U.P. College of Education in Education Quarterly. Volume 66, No. 1.

[10] Sentones, Alce M. (2010). Engaging the ADHD Learner in the Learning Environment. Grade School Faculty, La Salle Green Hills, Mandaluyong, Philippines. 